\title{
A pathway for the biogenesis of trans-acting siRNAs in Arabidopsis
}

\author{
Manabu Yoshikawa, Angela Peragine, Mee Yeon Park, and R. Scott Poethig ${ }^{1}$ \\ Department of Biology, University of Pennsylvania, Philadelphia, Pennsylvania 19104-6018, USA
}

\begin{abstract}
The Arabidopsis genes, TAS2 and TAS1a, produce structurally similar noncoding transcripts that are transformed into short (21-nucleotide [nt]) and long (24-nt) siRNAs by RNA silencing pathways. Some of these short siRNAs direct the cleavage of protein-coding transcripts, and thus function as trans-acting siRNAs (ta-siRNAs). Using genetic analysis, we defined the pathway by which ta-siRNAs and other short siRNAs are generated from these loci. This process is initiated by the miR173-directed cleavage of a primary poly(A) transcript. The 3' fragment is then transformed into short siRNAs by the sequential activity of SGS3, RDR6, and DCL4: SGS3 stabilizes the fragment, RDR6 produces a complementary strand, and DCL4 cleaves the resulting double-stranded molecule into short siRNAs, starting at the end with the miR173 cleavage site and proceeding in 21-nt increments from this point. The $5^{\prime}$ cleavage fragment is also processed by this pathway, but less efficiently. The DCL3-dependent pathway that generates long siRNAs does not require miRNA-directed cleavage and plays a minor role in the silencing of these loci. Our results define the core components of a post-transcriptional gene silencing pathway in Arabidopsis and reveal some of the features that direct transcripts to this pathway.
\end{abstract}

[Keywords: PTGS; RNAi; miRNA; trans-acting siRNAs]

Supplemental material is available at http://www.genesdev.org.

Received July 7, 2005; revised version accepted August 2, 2005.

MicroRNAs (miRNAs) and small interfering RNAs (siRNAs) are 20-24-nucleotide (nt) noncoding RNAs that repress gene expression through sequence-specific interactions with RNA or DNA (Bartel 2004; Tomari and Zamore 2005). These small RNAs serve as guide molecules for protein complexes that mediate RNA degradation, translational repression, or heterochromatin production. miRNAs and siRNAs are distinguished by the structure of their precursors and by their targets. miRNAs are cleaved from the short, imperfectly paired stem of a much larger foldback transcript and regulate the expression of transcripts to which they may have limited similarity. siRNAs arise from a long, perfectly paired double-stranded RNA (dsRNA) and typically direct the cleavage of transcripts to which they are completely complementary, including the transcript from which they are derived. Recently, we (Peragine et al. 2004) and others (Vazquez et al. 2004b; Allen et al. 2005; Williams et al. 2005) described a novel class of endogenous siRNAs in Arabidopsis termed "trans-acting siRNAs" (ta-siRNAs). ta-siRNAs are endogenous siRNAs that direct the cleavage of nonidentical transcripts. ta-siRNAs are therefore functionally similar to miRNAs in that they regulate the expression of genes to which they have limited similarity.

${ }^{1}$ Corresponding author.

E-MAIL spoethig@sas.upenn.edu; FAX (215) 898-8780.

Article published online ahead of print. Article and publication date are at http://www.genesdev.org/cgi/doi/10.1101/gad.1352605.
miRNAs were first discovered as components of the heterochronic pathway in Caenorhabditis elegans (Lee et al. 1993; Reinhart et al. 2000) and have since been found in abundance in animals and plants (http://microrna. sanger.ac.uk/sequences), where they regulate a wide variety of developmental and physiological processes (Ambros 2004; Kidner and Martienssen 2005). The normal function of endogenous siRNAs is less well understood. siRNAs derived from transposons and highly repeated centromeric sequences have been identified in several organisms and are thought to contribute to the transcriptional silencing of these sequences (Aravin et al. 2001, 2003; Diikeng et al. 2001; Hamilton et al. 2002; Llave et al. 2002a; Rudenko et al. 2003; Sijen and Plasterk 2003; Chicas et al. 2004; Xie et al. 2004). Endogenous siRNAs are likely to have a broader range of functions in C. elegans and Arabidopsis, however, as both of these organisms also produce siRNAs from single copy protein-coding and noncoding transcripts (Llave et al. 2002a; Reinhart et al. 2002; Ambros et al. 2003; Xie et al. 2004).

Plants produce two major size classes of siRNAs from endogenous transcripts and transgenes: $\approx 24$-nt siRNAs (long siRNAs), and $\approx 21$-nt siRNAs (short siRNAs) (Hamilton and Baulcombe 1999; Tang et al. 2003). These types of siRNAs are produced by different pathways and have different functions. Genetic analysis in Arabidopsis indicates that long siRNAs are generated from transcripts produced by the RNA polymerase, POL IV (Herr 
et al. 2005; Onodera et al. 2005; Yu et al. 2005), and require the RNA-dependent RNA polymerase (RdRp) RDR2, the Dicer-like protein DCL3 (Xie et al. 2004), the Argonaute protein AGO4 (Zilberman et al. 2003), and the methyl transferase HEN1 (Liu et al. 2004) for their biogenesis and/or stability. Long siRNAs mediate transcriptional silencing by promoting DNA and histone methylation (Hamilton and Baulcombe 1999; Zilberman et al. 2003; Liu et al. 2004; Xie et al. 2004). Although most endogenous siRNAs are of this type, the biological function of this class of siRNAs is unknown because morphological or physiological phenotypes associated with mutations in the above-mentioned genes have not been described. ta-siRNAs and other short siRNAs are associated with post-transcriptional gene silencing (PTGS, also known as RNAi) and require the RdRp RDR6/SDE1/SGS2 (hereafter called RDR6) and novel plant-specific protein SGS3 (Peragine et al. 2004; Vazquez et al. 2004b; Allen et al. 2005). Mutations in $R D R 6$ and $S G S 3$ affect the timing of vegetative phase change and floral morphogenesis (Peragine et al. 2004), implying that at least some of the endogenous targets of small siRNAs have important biological functions.

Five loci have been shown, or predicted, to generate ta-siRNAs in Arabidopsis. Three of these (TAS1a, $T A S 1 b$, and $T A S 1 c$ ) produce identical or very closely related ta-siRNAs that target a group of related genes of unknown function (Peragine et al. 2004; Vazquez et al. 2004b). TAS3 produces a ta-siRNA directed against the auxin-related transcription factors $A R F 2, A R F 3$, and ARF4 (Allen et al. 2005; Williams et al. 2005). TAS2 has been predicted to produce ta-siRNAs that target the pentatricopeptide repeat $(P P R)$ genes, At1g12770 and Atlg63130 (Allen et al. 2005), although there is still no evidence for this function. Allen et al. (2005) showed that the production of siRNAs from TAS2 and TAS1a in a heterologous system requires miR173-directed cleavage of their primary transcripts and presented evidence that the biogenesis of ta-siRNAs from TAS3 may also be mediated by miRNA-directed cleavage.

Here we show that TAS2 and TAS1a produce tasiRNAs directed against $P P R$ genes and are likely to represent homologous loci. These genes produce structurally related noncoding transcripts that are processed into both short and long siRNAs. Genetic analysis of the biogenesis of short siRNAs demonstrated that this class of siRNAs is produced exclusively from the miRNA-generated cleavage fragments of TAS2 and TAS1a by a pathway involving SGS3, RDR6, and DCL4. Our results provide a comprehensive picture of this pathway and suggest the likely functions of these proteins in PTGS in plants.

\section{Results}

At2g39680 (TAS2) is a source of ta-siRNAs

At2g39680 (TAS2) was identified in a microarray analysis of RNA levels in zip-1, sgs3-11, and rdr6-11 (Peragine et al. 2004). Among the genes identified in this study, TAS2 was unique in that it was elevated approximately fourfold in $r d r 6-11$ but was not affected by zip-1 or sgs3-
11. A search of the ASRP database (Gustafson et al. 2005) revealed that many siRNAs have been cloned from TAS2. BLAST searches conducted with these cloned siRNAs did not reveal obvious targets. However, searches conducted with the hypothetical TAS2 coding sequence indicated that it has four 20-30-nt regions with reverse complementarity to a family of $P P R$ genes located on chromosome 1 (Fig. 1A; Lurin et al. 2004).

To determine if these $P P R$ transcripts are cleaved at these complementary sites, we took advantage of an RNA ligase-mediated rapid amplification of $5^{\prime} \mathrm{cDNA}$ ends (RLM-5' RACE) protocol that has been widely used to identify cleavage sites in mRNA (Liu and Gorovsky 1993). For each of the three transcripts tested (At1g63130, At1g63230, and At1g62930), RLM-5' RACE yielded PCR products of the expected size with wild-type RNA (Fig. 1B). Sequencing of these products revealed that each transcript is cleaved in the middle of the complementary region, at a site located $10 \mathrm{nt}$ from a 3' A (Fig. 1A); this is the pattern expected for cleavage mediated by a miRNA or siRNA (Elbashir et al. 2001; Llave et al. 2002b; Kasschau et al. 2003). Three closely spaced cleavage sites were identified in At1g62930, suggesting that this gene is targeted by several related siRNAs (see below). Blots of low-molecular-weight (LMW) RNA hybridized with oligonucleotide probes complementary to the TAS2 sequences in Figure $1 \mathrm{~A}$ and to the cloned TAS2 siRNA, siR1511, revealed 21-nt siRNAs corresponding to these sequences in wild-type and zip-1 plants, but not in sgs3-11 and rdr6-11 (Fig. 1C). Consistent with this result, cleavage products from Atlg63130, Atlg63230, and At1g62930 could not be detected by RLM-5'RACE in these mutants (Fig. 1B); furthermore, quantitative RTPCR performed with primers that flank the cleavage sites in Atlg63130 and Atlg62930 revealed that these transcripts are elevated two- to threefold in both mutants (Fig. 1D). sgs3-11 and rdr6-11 had only a small effect on the accumulation of Atlg63230, indicating that siRNAs play a minor role in the regulation of this gene. To confirm that these transcripts are targets of TAS2derived siRNAs, we examined the phenotype of a $\mathrm{T}$ DNA insertion in TAS2 (Fig. 2A) that reduces the production of siR1511 but does not affect the production of the TAS1a ta-siRNA, siR255 (Fig. 1E). The abundance of At1g63130, Atlg63230, and At1g62930 in plants homozygous for SALK_014168 was intermediate between the wild-type level and the level in sgs3-11 or rdr6-11 (Fig. 1D), consistent with the intermediate level of siR1511 in this mutant (Fig. 1E). We conclude that TAS2 produces at least four distinct ta-siRNAs directed against $P P R$ genes. SALK_014168 does not have an obvious effect on shoot morphology (data not shown), so the hyperaccumulation of PPR transcripts in sgs3-11 and rdr6-11 does not account for their precocious vegetative phenotype (Peragine et al. 2004).

\section{The primary transcripts of TAS2}

The transcripts produced from TAS2 were characterized in detail to determine how ta-siRNAs are generated from 


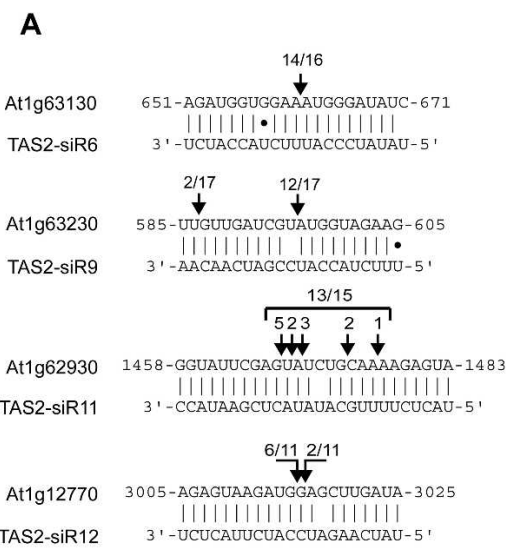

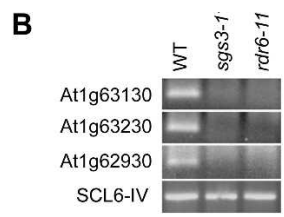

D

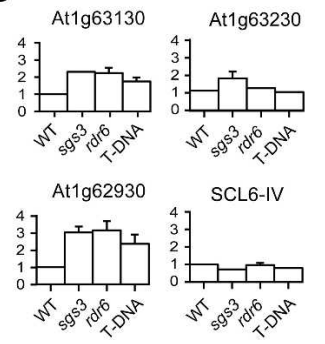

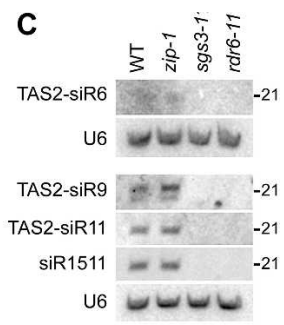

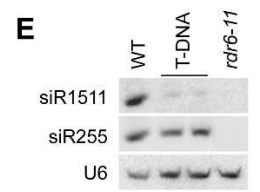

Figure 1. At2g39680 (TAS2) produces ta-siRNAs that target PPR genes. (A) Sequences in TAS2 that have reverse complementarity to mRNAs encoding PPR proteins. Fractions indicate the number of sequenced RLM- 5 'RACE clones that terminated at the indicated position. (B) sgs3-11 and rdr6-11 prevent the formation of RLM-5'RACE products from PPR transcripts targeted by siRNAs from TAS2. Amplification of the miR171 target, SCL6-IV, occurs normally in these mutants. $(C)$ Blots of LMW RNA hybridized with oligo nucleotide probes complementary to the TAS2 sequences in $A$ and to the cloned TAS2 siRNA, siR1511. U6 was used as loading control. (D) Quantitative real-time RT-PCR analysis of the abundance of PPR transcripts in total RNA from wild type (WT), sgs3-11, rdr6-11, and plants homozygous for the SALK_014168 T-DNA insertion. PCR was performed with primers that flank the cleavage site in these transcripts. Three to six biological replicates were performed for each sample. Values were normalized to EIF4A and are expressed as the ratio of the value relative to wild type. (E) Blot of LMW RNA from wild type (WT), two families of plants homozygous for the SALK_014168 T-DNA insertion, and rdr6-11 hybridized with probes to the indicated siRNAs.

this locus. Several existing TAS2 cDNAs were obtained from the Arabidopsis Biological Resource Center and resequenced (Fig. 2A). The predicted TAS2 open reading frame (ORF) is present in a 659-bp clone that has no poly(A) tail (GenBank BT011210). This ORF is unusually short and is not conserved in other plants, and so is unlikely to actually encode a protein. The other cDNAs from this region have a poly(A) tail and are antisense to this clone. The longest of these, M74P20STM /GenBank DQ000174), is $993 \mathrm{nt}$. A 602-nt clone, 205C13 (GenBank DQ000172), terminates in the middle of M74P20STM but has the same $3^{\prime}$ end, suggesting that it represents a derivative of this longer transcript. Because most siRNAs from this locus correspond to the strand represented by these clones, we refer to this strand as the $(+)$ strand, and refer to the strand that contains the ORF as the $(-)$ strand.

The primary TAS2 transcripts were identified by performing $5^{\prime}$ and $3^{\prime}$ RACE with primers specific for $(+)$ or $(-)$ strands. Two (+) transcripts were identified by 3' RACE performed with a primer located near the 5' end of M74P20STM (Fig. 2A). Both transcripts have the same 3' end, but TAS2(+) (GenBank DQ000170) contains a 569 -nt intron that is spliced out of TAS2 $(\Delta+)($ GenBank DQ000171). 5' RACE performed with a primer within this intron and a primer on the $3^{\prime}$ side of the intron produced products with the same $5^{\prime}$ end, suggesting $T A S 2(+)$ and $T A S 2(\Delta+)$ are transcribed from the same promoter. This experiment also suggests that these transcripts have a 5' cap, since uncapped transcripts are not amplified by the standard 5' RACE protocol. The 5' end determined by this approach is located $62 \mathrm{nt}$ upstream of the $5^{\prime}$ end of the M74P20STM cDNA. Attempts to de- termine the $5^{\prime}$ and $3^{\prime}$ ends of the $(-)$ transcript failed, probably because of the low abundance of this transcript (see below).

To identify cleaved TAS2(+) transcripts, total floral RNA was subjected to RLM-5' RACE, using a primer located near the $3^{\prime}$ end of $T A S(+)$. This experiment yielded products that terminated at a single site within the intron in TAS2(+). This site is identical to the $5^{\prime}$ end of the cDNA 205C13 (Fig. 2A), indicating this cDNA corresponds to a $3^{\prime}$ cleavage fragment of TAS2(+). The corresponding $5^{\prime}$ cleavage fragment was characterized by amplifying self-ligated transcripts by RT-PCR (Couttet et al. 1997). This experiment identified a transcript with a $5^{\prime}$ end that matches the $5^{\prime}$ end of the $(+)$ transcript, and a $3^{\prime}$ end that terminates at the cleavage site identified by RLM-5' RACE. Three out of 12 self-ligated clones had one or two untemplated adenines at their $3^{\prime}$ end. Untemplated uridines are added to the $3^{\prime}$ end of the cleavage fragments of some miRNA-targeted transcripts in Arabidopsis (Shen and Goodman 2004), suggesting that the 5 ' fragment of TAS2(+) may be processed in a similar fashion. We conclude that TAS2(+) is cleaved into a 442nt $5^{\prime}$ fragment, TAS2 $\left(+5^{\prime}\right)$, and a 613-nt 3' fragment, TAS2(+3'), by an RNAi-like mechanism (Fig. 2A).

The transcripts produced from TAS2 were further characterized by hybridizing blots of total and poly(A) RNA from wild-type Columbia (Col) and rdr6-11 mutants with a double-stranded probe (p1) that spans this cleavage site, as well as with short strand-specific probes (Fig. 2C). All of the transcripts detected with the $\mathrm{p} 1$ probe hybridized to $(+)$ strand-specific probes but not to (-) strand-specific probes, demonstrating that TAS2 is transcribed primarily in the $(+)$ orientation (Fig. 2D; data 
A

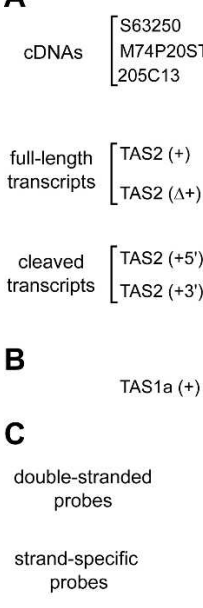

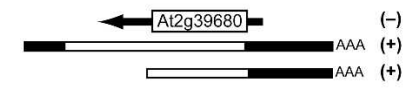

miR173 SALK 014168
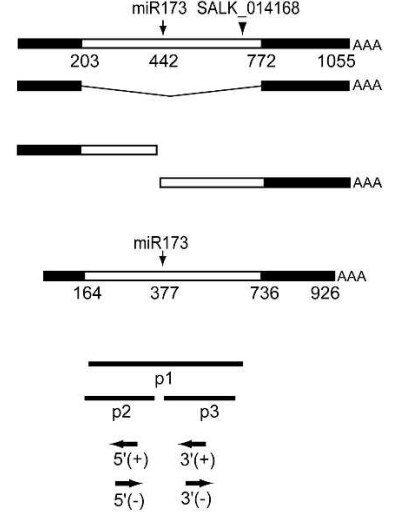

D

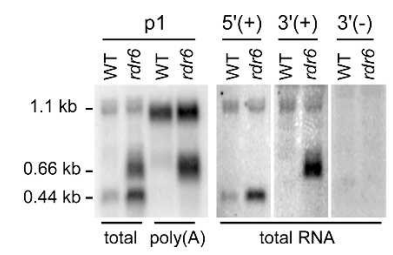

E

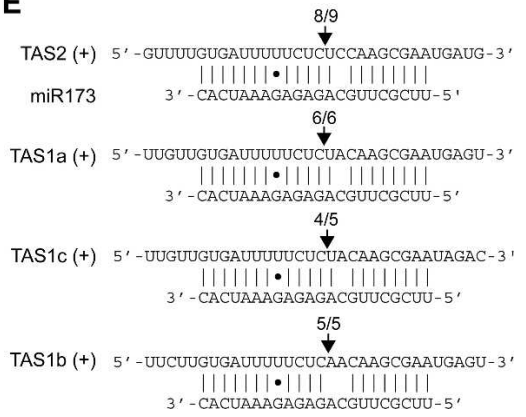

Figure 2. TAS2(+) and TAS1(+) are cleaved by miR173. (A) Schematic illustration of TAS2 cDNAs and transcripts identified by $5^{\prime}$ and 3' RACE, RLM-5'RACE, and RT-PCR of self-ligated RNA. (Black box) Exon; (open box) intron. (B) Structure of the unspliced TAS1a(+) transcript (Vazquez et al. 2004b). (C) DNA probes used in this study. Similarly positioned probes were used for TAS2 and TAS1a. (D) Blots of total and poly(A)-selected RNA hybridized with the indicated TAS2 probes. The abundance of the $\approx 1-\mathrm{kb}$ polyadenylated $(+)$ transcript is not affected by rdr6-11; however, the $0.44-\mathrm{kb}$ nonadenylated $5^{\prime}(+)$ fragment and the $0.66-\mathrm{kb}$ polyadenylated 3' (+) fragment accumulate to high levels in this mutant. $(E)$ TAS2 $(+)$ and TAS1 $(+)$ transcripts are cleaved at the miR173 target site. Fractions indicate the number of RLM-5' RACE clones that terminated at the indicated position.

not shown). In wild-type plants, $\mathrm{p} 1$ hybridized to a 1.1-kb $(+)$ transcript and a $0.44-\mathrm{kb}(+)$ transcript in total RNA, and a $1-\mathrm{kb}(+)$ transcript in poly(A) RNA. The 1-kb polyadenylated $(+)$ transcript and the $0.44-\mathrm{kb}$ nonadenylated $(+)$ transcript correspond, respectively, to $T A S 2(+)$ and TAS2 $\left(+5^{\prime}\right)$; the relationship between this $1-\mathrm{kb}$ transcript and the $1.1-\mathrm{kb}$ transcript observed in total RNA is unclear because the apparent difference in the size of these transcripts could be an artifact of the difference in the amount of RNA loaded on these gels. rdr6-11 plants had very high levels of TAS2 $\left(+5^{\prime}\right)$ and a polyadenylated $0.66-\mathrm{kb}$ transcript corresponding to TAS2 $\left(+3^{\prime}\right)$ but had wild-type levels of the 1.1-kb (+) transcript (Fig. 2D). No hybridization was detected with (-) strand probes, indicating that $T A S 2\left(+5^{\prime}\right)$ and $T A S 2\left(+3^{\prime}\right)$ accumulate as single-stranded molecules in this mutant. These results indicate that the cleavage fragments of TAS2 $1+1$ - but not TAS2(+) itself-are the targets of an RDR6-dependent silencing pathway. The $3^{\prime}$ fragment appears to be processed more efficiently than the $5^{\prime}$ fragment because it is present at much lower levels than the $5^{\prime}$ fragment in wild-type plants (Fig. 2D). The (-) transcript of TAS2 is also present at very low levels because it was not detected with $(-)$ strand probes.

TAS2 is targeted by miR173 and is homologous to TAS1a, TAS1b, and TAS1c

A comparison of the cleavage site in TAS2 (+) with the sequence of known miRNAs revealed that miR173 can potentially pair with this sequence with one mismatch and a single G-U pair (Fig. 2E). As is typical for miRNA- directed cleavage (Kasschau et al. 2003), the cleavage site in TAS2(+) is $10 \mathrm{nt}$ from the $5^{\prime}$ end of miR173. Three previously identified sources of ta-siRNAs-TAS1a (At2g27400/cluster64), TAS1b (At1g50055/cluster 28), and TAS1c (At2g39675/cluster 68)-have a sequence that is nearly identical to this putative miR173 target sequence and are cleaved at the same site within this sequence as TAS2(+) (Fig. 2E). TAS1a resembles TAS2 in that it produces a $1-\mathrm{kb}$ primary transcript with a single $\approx 570$-nt differentially spliced intron (Vazquez et al. 2004b). The miR173 site is located within this intron in the same position as the miR173 site in TAS2 (Fig. 2A,B). Although the TAS1 loci do not have extended sequence similarity to TAS2, all three loci can theoretically produce siRNAs that target PPR genes (Fig. 3A,B). Indeed, the location of the cleavage sites in Atlg12770 indicate that it is targeted by a ta-siRNA from TAS1a, as well as by a ta-siRNA from TAS2 (Fig. 3C). These observations, and the fact that $T A S 2$ is immediately adjacent to $T A S 1 c$ on chromosome 2 , strongly suggest that TAS1a, TAS1b, TAS1c, and TAS2 are paralogous loci.

miRNA-directed cleavage is required for the biogenesis of short, but not long, siRNAs

Indirect evidence that miR173-directed cleavage is required for the biogenesis of ta-siRNAs and other short siRNAs from TAS2(+) and TAS1a|+) is provided by the arrangement of short siRNAs within these transcripts (Fig. 3A; Vazquez et al. 2004b; Allen et al. 2005). Most of the siRNAs that have been cloned from these loci, as well as all the hypothetical ta-siRNAs that target $P P R$ genes, are spaced in near perfect 20-21-nt increments 
A

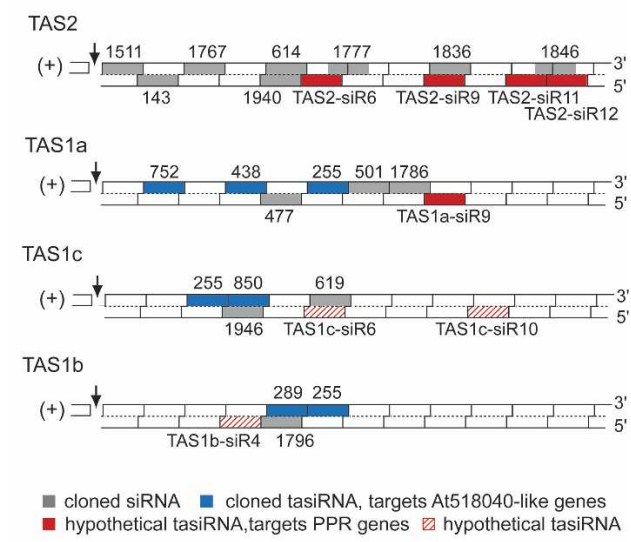

B
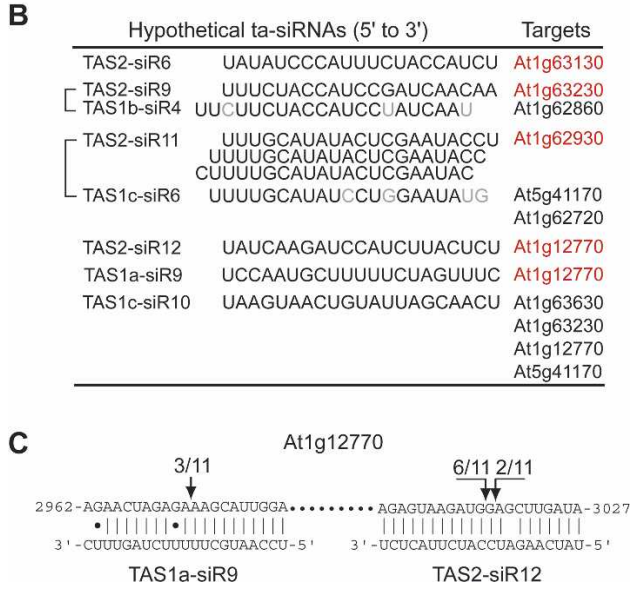

Figure 3. The position and predicted nucleotide sequence of TAS2 and TAS1 siRNAs. (A) siRNAs arising from the $3^{\prime}$ fragment of TAS2, TAS1a, TAS1c, and TAS1b are positioned in 21-nt increments relative to the miR173 cleavage site (arrow). The sequence of these siRNAs is available from http://asrp. cgrb.oregonstate.edu. siRNAs in boxes are within $2 \mathrm{nt}$ of the site predicted by a 21 -nt spacing pattern. $(B)$ The sequence of hypothetical ta-siRNAs from TAS2 and TAS1a, and the PPR genes targeted by these ta-siRNAs. Transcripts that are cleaved $10 \mathrm{nt}$ from the $5^{\prime}$ end of the ta-siRNA are in red. Sequences that are similar in TAS2 and TAS1a are indicated by a bracket. (C) At $\lg 12770$ has two closely spaced cleavage sites potentially targeted by ta-siRNAs from TAS2 and TAS1a.

and are in perfect register with the miR173 cleavage site. Most significantly, the TAS2 ta-siRNAs that target PPR genes are located in the sixth, ninth, 11 th, and 12 th positions from this site (Fig. 3A). This spacing pattern is consistent with the evidence that Dicer cleaves doublestranded RNA sequentially from the end of the molecule (Elbashir et al. 2001; Ketting et al. 2001; Zhang et al. 2002; Siolas et al. 2004) and suggests that that miR173directed cleavage is essential for the production of tasiRNAs because this event generates an end that is an appropriate substrate for DCL.

Loss-of-function mutations in DCL1, HYL1, and HST reduce or eliminate the accumulation of many miRNAs but have no effect on post-transcriptional transgene silencing (Park et al. 2002, 2005; Finnegan et al. 2003; Han et al. 2004; Vazquez et al. 2004a), suggesting that these genes are involved primarily, if not exclusively, in the processing of miRNAs. miR173 was absent in $d c 11-7$, reduced in hyl-2, and was not affected by hst-6 (Fig. 4A). Consistent with the effect of these mutations on miR173, cleavage of TAS2(+) was completely abolished in $d c 11-7$ and reduced in hyl-2 but occurred normally in hst-6 (Fig. 4B). The accumulation of siR1511 and siR255 was directly correlated the amount of transcript cleavage in these mutants: These siRNAs were missing in $d c 11-7$, present at reduced levels in hyl-2, and unaffected by hst-6 (Fig. 4A). These results support the conclusion that the biogenesis of short siRNAs from TAS2 and TAS1a requires miRNA-directed cleavage of their primary transcripts.

There is evidence that miRNAs associate with their target transcripts during transcription (Bao et al. 2004), but when and where they direct the cleavage of these transcripts is still unknown. The effect of SALK_014168 on the accumulation of the $5^{\prime}$ cleavage fragment of TAS2(+) suggests that cleavage of this transcript occurs after transcription is completed. Because the SALK_014168 T-DNA is inserted 3' of the miR173 cleavage site (Fig. 2A), it should not interfere with the production of the $5^{\prime}$ fragment if this fragment is generated during transcription. However, plants homozygous for this T-DNA produce reduced amounts of the 5 ' fragment of TAS2(+), and also produce an array of large transcripts
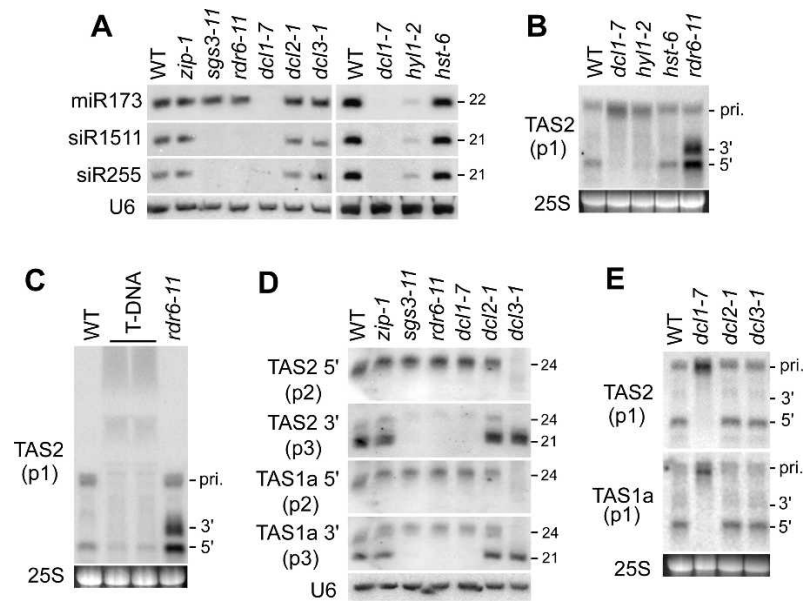

Figure 4. Production of ta-siRNAs from TAS2(+) and TAS1a|+| requires miR173-directed cleavage. Blots of LMW RNA $(A, C)$ or total RNA $(B, D)$ hybridized with the indicated probes. $(A) \mathrm{Mu}-$ tations that interfere with the biogenesis of miR 173 have correlated effects on the accumulation of siR1511 and siR255. (B) Cleavage of TAS2(+) in dcl1-7, hyl1-2, and hst-6 is inversely correlated with the abundance of miR173 in these mutants. $(C)$ A T-DNA-inserted $3^{\prime}$ of the miR173 cleavage site destabilizes TAS2(+) and reduces the accumulation of the $5^{\prime}$ cleavage fragment. $(D)$ The $5^{\prime}$ and $3^{\prime}$ portions of TAS2 and TAS1a produce different size classes of siRNAs. Production of 24-nt siRNAs requires DCL3 but not DCL1. $(E) d c 12-1$ and dcl3-1 have no effect on the accumulation of TAS2(+) and TAS1a(+) or their cleavage products. See Figure $2 B$ for the location of the probes used in these experiments. 
that probably correspond to partially degraded cleaved and uncleaved transcripts containing the T-DNA (Fig. 4C). This result demonstrates that the presence of the T-DNA destabilizes TAS2(+) and suggests that the reduced accumulation of $5^{\prime}$ fragment can be attributed to the post-transcriptional instability of the mutant transcript.

To obtain a more complete picture of the processing of TAS2 and TAS1a, blots of LMW RNA and total RNA from various mutants were hybridized with long, double-stranded probes to the $5^{\prime}(\mathrm{p} 2)$ and $3^{\prime}(\mathrm{p} 3)$ parts of these transcripts, as well as with a probe (p1) that spans the miR173 cleavage site. Blots of LMW RNA revealed that the $5^{\prime}$ region of these transcripts produces predominantly long siRNAs, whereas the $3^{\prime}$ region produces both long and short siRNAs, with short siRNAs being the more abundant class (Fig. 4D). zip-1 and dcl2-1 had no effect on the silencing of these loci. sgs3-11, rdr6-11, and dc11-7 prevented the accumulation of short siRNAs, but had little or no effect on the accumulation of long siRNAs, whereas $d c 13-1$ exclusively prevented the accumulation of long siRNAs. In contrast to $d c 11-7, d c 12-1$ and $d c 13-1$ had no effect on the accumulation of the primary TAS2 and TAS1a transcripts or their cleavage fragments (Fig. 4E). These results demonstrate that the biogenesis of long siRNAs does not require miRNAdirected cleavage and also indicate that long siRNAs are generated by a pathway distinct from the one that produces small siRNAs. The long siRNA pathway does not appear to contribute significantly to the silencing of TAS2(+) and TAS1a|+) because the accumulation of these transcripts is not affected by $d c 13-1$ (Fig. 4E).

\section{SGS3 and RDR6 act sequentially on the TAS2 $(+)$ and TAS1a(+) cleavage fragments}

It is evident from the elevated level of TAS2 $\left(+3^{\prime}\right)$ and TAS2 $\left(+5^{\prime}\right)$ in $r d r 6-11$ that these fragments are silenced by the RDR6 pathway. Is the primary TAS2(+) transcript also silenced by this pathway? Although we did not observe an increase in TAS2(+) in rdr6-11 plants (Fig. 2D), this transcript may be protected by its association with miR173-primed RNA-induced silencing complex (RISC). To eliminate this possibility, we examined the accumulation of TAS2(+) in dcl1-7 rdr6-11 double mutants, in which miR173 is absent and TAS2(+) is not cleaved. Double mutants had the same amount of TAS2(+) as dc11-7 (Fig. 5A), confirming that that this transcript is not a substrate for the RDR6 pathway.

SGS3 acts in same pathway as RDR6 (Beclin et al. 2002; Peragine et al. 2004; Vazquez et al. 2004b), but its specific function and the order in which these genes operate is still unknown. To address these questions, we examined the accumulation of TAS2(+) and TAS1a(+) in sgs3-11 and sgs3-11 rdr6-11 double mutants. In contrast to $r d r 6-11-$ which causes a significant increase in the level of the cleavage fragments of these transcriptssgs3-11 reduced the accumulation of the 5' fragment, and completely eliminated the $3^{\prime}$ fragment (Fig. 5B). sgs3-11 rdr6-11 double mutants had the same low level

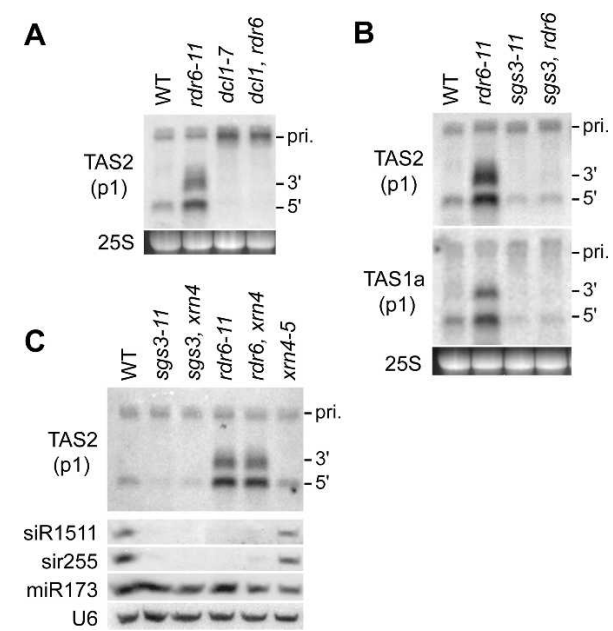

Figure 5. Epistasis analysis of the function of SGS3, RDR6, and XRN4. Blots of total RNA $(A-C)$ and LMW RNA $(C)$ hybridized with the indicated probes. $(A) d c 11-7 \mathrm{rdr6}-11$ double mutants are indistinguishable from $d c 11-7 .(B)$ sgs3-11 reduces the accumulation of the TAS2 $(+)$ and TAS1al+| cleavage fragments and is epistatic to $r d r 6-11$. (C) xrn4-1 does not affect the accumulation of TAS2(+) and its cleavage fragments (top) and also has no effect on siRNAs derived from TAS2 and TAS1a (bottom).

of these fragments as sgs3-11, indicating that $S G S 3$ is required for the accumulation of these cleavage fragments in rdr6-11 mutants; i.e., sgs3-11 is completely epistatic to rdr6-11. These results indicate that SGS3 directly or indirectly stabilizes these cleavage fragments and acts before RDR6.

The phenotype of sgs3-11 suggests that SGS3 somehow protects the cleavage fragments of TAS2(+) and TAS1a|+| from RNases that act on single-stranded RNA. One such RNase is XRN4. XRN4 is a cytoplasmically localized 5' -3 ' exonuclease that degrades the 3 ' cleavage fragments of some miRNA-targeted genes (Souret et al. 2004) and decapped mRNAs (Gazzani et al. 2004). It is of particular interest because there is evidence that it competes with RDR6 (Gazzani et al. 2004). However, xrn4-5 had no effect on the accumulation of TAS2(+) or its cleavage products, either as a single mutant, or in combination with sgs3-11 or rdr6-11 (Fig. 5C). xrn4-5 also had no effect on the accumulation of TAS2 or TAS1a siRNAs (Fig. 5C). These results demonstrate that TAS2 is not a substrate of XRN4. The possibility that TAS2 is a substrate of the related exonucleases XRN2 or XRN3 (Souret et al. 2004) remains to be tested.

\section{Small siRNAs are generated by DCL4}

Screens of EMS-mutagenized plants produced a recessive mutation that is morphologically indistinguishable from sgs3-11 and rdr6-11 but complements both of these mutations (Fig. 6A). This mutation was mapped by genetic crosses to a region on chromosome 5 containing DCL4 and was found to be associated with a point mutation in the helicase domain of DCL4 that converts glutamic acid 
A

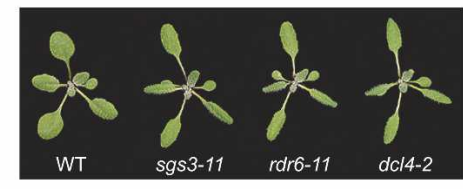

B
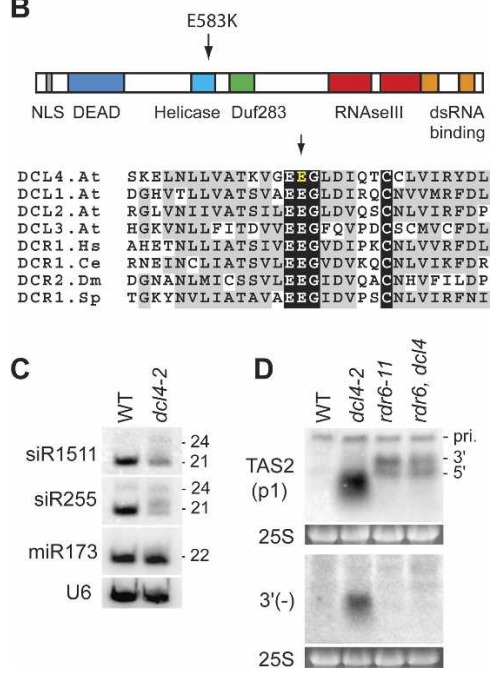

Figure 6. DCL4 is a component of the SGS3/RDR6 pathway and acts downstream of RDR6. (A) Two-week-old wild-type and mutant plants. The vegetative phenotype of $d c 14-2$ is identical to that of sgs3-11 and $r d r 6-11$. (B) The domain structure of the DCL4 protein (Schauer et al. 2002) and the location of the $d c 14-2$ mutation. dcl4-2 affects a glutamic acid that is completely conserved in Dicers from Arabidopsis (At), Homo sapiens (Hs), C. elegans (Ce), Drosophila melanogaster (Dm), and S. pombe (Sp). (C) dc14-2 interferes with the biogenesis of siR1511 and siR255 but does not affect miR173. (D) dcl4-2 accumulates an array of small transcripts, some of which hybridize to an oligonucleotide probe specific for the $(-)$ strand of TAS2 $\left(3^{\prime}\right)$. These small transcripts are not produced in rdr6-11 dcl4-2 double mutants.

at position 583 to lysine (Fig. 6B). This nonconservative mutation (dc14-2) is in the middle of a short amino acid sequence that is perfectly conserved in Dicers from Arabidopsis, humans, Drosophila, C. elegans, and Schizosaccharomyces pombe and is therefore likely to have a major effect on the function of DCL4. A T-DNA insertion in DCL4 (dc14-1; FLAG_330A04) generated in the Ws ecotype has a morphological phenotype similar to that of $d c 14-2$, indicating that this phenotype is attributable to DCL4.

dc14-2 had normal levels of miR173 (Fig. 6C) and did not affect the accumulation of the primary TAS2(+) transcript (Fig. 6D), demonstrating that DCL4 is not required for the biogenesis or function of this miRNA. However, mutant plants had reduced amounts of the 21-nt forms of siR1511 and siR255 and accumulated unusually large forms of these siRNAs (Fig. 6C). This result suggests that DCL4 is directly involved in the production of these siRNAs and that other DCLs are capable of acting on the substrates of this enzyme in a dcl4-2 mutant background. This conclusion is supported by the effect of dc14-2 on the processing of the TAS2(+) cleavage fragments. Blots of total RNA hybridized with the p1 probe revealed that $d c 14-2$ accumulates an array of transcripts smaller than $400 \mathrm{nt}$ (Fig. 6D). These transcripts also hybridize to a probe for the $(-)$ strand of the 3 ' fragment (Fig. $6 \mathrm{D})$, suggesting that at least some of these transcripts are aberrantly processed, double-stranded forms of the $3^{\prime}$ cleavage fragment. Consistent with this interpretation, rdr6-11 dcl4-2 double mutants lacked these small transcripts, and instead accumulated single-stranded, fulllength $5^{\prime}$ and 3 ' fragments of TAS2(+). That is, double mutants were indistinguishable from $r d r 6-11$. This result demonstrates that RDR6 is required for the production of the small transcripts present in $d c 14-2$, and thus acts before DCL4. The observation that rdr6-11 blocks the production of $(-)$ transcripts complementary to TAS2 $\left(+3^{\prime}\right)$ is evidence that RDR6 functions as a RdRp. The epistatic relationship between $r d r 6-11$ and $d c 14-2$ is also significant because it demonstrates that the substrate of DCL4 is double-stranded RNA.

\section{Discussion}

In this paper, we describe the pathway by which small siRNAs are generated from the TAS2 and TAS1a loci in Arabidopsis. Although these transcripts have the special feature of being cleaved by a miRNA, this pathway is unlikely to be restricted to this class of transcripts because two of its components, SGS3 and RDR6, are required for PTGS of sense transgenes and for resistance to some viruses (Dalmay et al. 2000b; Mourrain et al. 2000; Beclin et al. 2002; Himber et al. 2003; Muangsan et al. 2004). The lessons learned from this analysis of the processing of TAS2 and TAS1a may therefore have broad implications for the mechanism of PTGS in plants.

\section{The SGS3/RDR6/DCL4 pathway}

A model for the way in which small siRNAs are generated from TAS2 and TAS1 $a$ is illustrated in Figure 7. This process is initiated by the miR173-mediated cleavage of a capped, polyadenylated transcript. The resulting cleavage fragments are then bound by SGS3, or by proteins associated with SGS3, thus protecting them from degradation by enzymes that act on single-stranded RNA. RDR6 transforms the fragments into doublestranded molecules, and DCL4 subsequently cleaves these fragments into 21-nt siRNAs. Although both the 5' and $3^{\prime}$ cleavage fragments of TAS2(+) and TAS1a $(+)$ are processed by SGS3, RDR6, and DCL4, the 3' fragment is processed more efficiently by this pathway than the $5^{\prime}$ fragment. This difference may be explained by the substrate specificity of Dicer. In vitro studies of siRNA biogenesis in animals indicate that Dicer cleaves siRNAs from the end of a dsRNA substrate and prefers molecules that have a 1- or 2-nt 3' overhang (Elbashir et al. 2001; Zhang et al. 2002, 2004; Siolas et al. 2004). Because of polarity of RNA synthesis, RDR6-mediated transcription of the $3^{\prime}$ fragment will frequently terminate at the 5' 


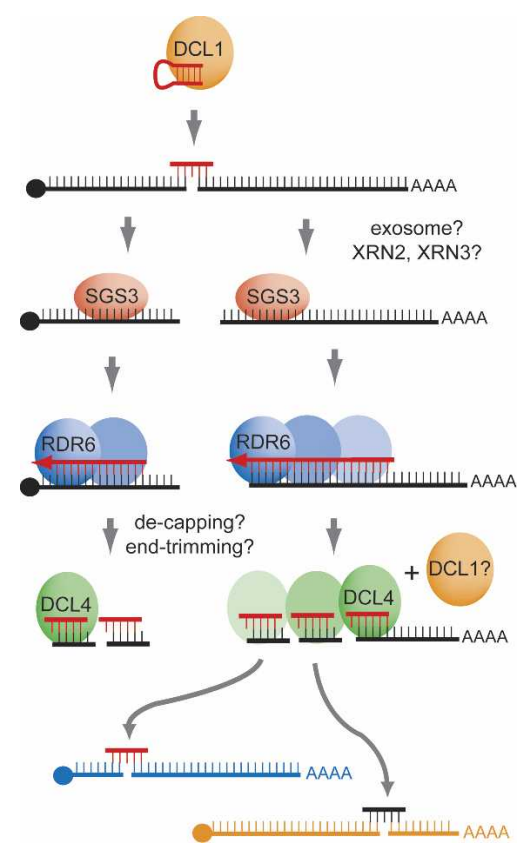

Figure 7. Model for the biogenesis of short siRNAs from TAS2(+) and TAS1a(+). The biogenesis of short siRNAs is initiated by cleavage of these transcripts by miR173. This event produces fragments that are protected from degradation by SGS3 and are subsequently transcribed by RDR6. The resulting double-stranded fragments are then cleaved into small siRNAs by DCL4 and possibly DCL1, starting at the end of the fragment. Some of these small siRNAs function as ta-siRNAs. The $3^{\prime}$ fragment is particularly susceptible to DCL4 because transcription by RDR 6 frequently terminates at the miR 173 cleavage site, yielding a duplex end. The $5^{\prime}$ fragment is less susceptible to DCL4 because transcription frequently begins internal to the $3^{\prime}$ end of this fragment, leaving a single-stranded end. Cleavage from the $5^{\prime}$ end of this fragment is inhibited by the $5^{\prime}$ cap.

end of this fragment; that is, at the miR173 cleavage site. If RDR6 adds untemplated nucleotides to the $3^{\prime}$ end of the newly transcribed strand-as has been found in the case of a tomato RdRp (Schiebel et al. 1993) -this will generate a duplex end with a 3 ' overhang and make this fragment an ideal substrate for DCL4 or a competing DCL. The observation that small siRNAs from the $3^{\prime}$ fragment are in exact register with the miR173 cleavage site provides strong support for this model. In contrast, initiation of transcription at random positions on the $5^{\prime}$ cleavage fragment will frequently yield molecules that have a single-stranded $3^{\prime}$ end, preventing processing of this end by Dicer; processing from the $5^{\prime}$ end is likely to be inhibited by the presence of the $5^{\prime}$ cap. These considerations suggest that processing of the $5^{\prime}$ fragment into ta-siRNAs (Allen et al. 2005) requires a special mechanism for directing RDR6 to the $3^{\prime}$ end of these fragments.

miRNA-directed cleavage cannot be the only factor that directs transcripts to this pathway, because most miRNA-targeted transcripts are not silenced by SGS3 and RDR6 (Peragine et al. 2004; Vazquez et al. 2004b). One factor that may account for the susceptibility of TAS2 is the presence of an antisense transcript. Al- though we were unable to detect this transcript on Northern blots, a cDNA representing the (-) strand of TAS2 has been identified. Hybridization between TAS2(+) and this transcript could yield primary siRNAs that serve as primers for RDR6. Because the (-) transcript overlaps extensively with the $3^{\prime}$ cleavage fragment, these primers would favor transcription of this fragment. Another factor that may direct the SGS3/RDR6/DCL4 pathway to TAS2(+) and TAS1a(+) is the presence of an unspliced intron. It is noteworthy that the miR173 site is located in this intron and that all of the ta-siRNAs generated from these transcripts are confined to this intron. Most Arabidopsis genes targeted by miRNAs have the miRNA target site in their coding region, and it is possible that the location of a miRNA target site in an intron, or in another post-transcriptionally processed part of a transcript (e.g., the 3' UTR) somehow makes the transcript unusually susceptible to PTGS. This hypothesis is consistent with the observation that the miR390 target site in TAS3 is located in a predicted $3^{\prime}$ UTR (Allen et al. 2005). Nonsense-mediated decay of mRNAs is mediated by an interaction between the RNA splicing apparatus and the proteins involved in translation (Maquat 2004), and it may be that interactions between the RNA splicing apparatus and RISC are important for directing transcripts to the SGS3/RDR6/DCL4 pathway. The fact that TAS2(+) and TAS1a(+) are noncoding transcripts may also be important because there is evidence in mammals that untranslated mRNAs are much more susceptible to RNAi than translated mRNAs (Gu and Rossi 2005).

\section{The functions of RDR6, SGS3, and DCL4}

Beclin et al. (2002) showed that RDR6 and SGS3 are required for PTGS of sense transgenes but not hairpin transgenes, from which they concluded that these proteins are required for the production of duplex RNA from a single-stranded template. This conclusion is supported in the case of RDR6 by its similarity to a tomato RNAdependent RNA polymerase (Dalmay et al. 2000b; Mourrain et al. 2000) and evidence that is required for the phenomenon of transitivity (Vaistij et al. 2002) and for the amplification and spread of transgene silencing (Himber et al. 2003). Our observation that rdr6-11 blocks the production of the TAS2 $\left(-3^{\prime}\right)$ transcripts in an $d c 14-1$ mutant background provides additional support for this conclusion and is the first direct evidence that RDR6 functions as an RdRp.

The biochemical function of SGS3 is less well defined. The effect of sgs3-11 on the accumulation of the cleavage fragments of TAS2|+) and TAS1a|+| demonstrates that SGS3 somehow stabilizes these single-stranded fragments, but whether it has a more direct role in the transformation of these transcripts into dsRNA is unknown. We suspect that SGS3 is actually required for the function of RDR6 because sgs3-11 eliminates the production of small siRNAs, and is completely epistatic to rdr6-11. If SGS3 merely has a protective function, one would imagine that sgs3-11 would have a less severe phenotype 
than rdr6-11 because transcripts that escape degradation in sgs3-11 mutants could be processed by RDR6. Whether SGS3 binds directly to RNA and, if so, the specific features that it recognizes, also remains to be determined. SGS3 encodes a coiled-coil protein with a zinc finger domain that could mediate RNA binding (Bateman 2002). It also has a conserved domain of unknown function, termed the XS domain. Other Arabidopsis proteins that have an XS domain have a second conserved domain called the XH domain, and it has been suggested that SGS3 functions in collaboration with one or more proteins that have this domain (Bateman 2002).

The Dicer responsible for PTGS in Arabidopsis has remained a mystery because none of the three previously described DCLs are good candidates. DCL1 is required for the biogenesis of miRNAs (Park et al. 2002) but is not required for PTGS of a hairpin transgene (Finnegan et al. 2003). DCL2 is required for the biogenesis of siRNAs from some viruses but has no apparent role in the generation of endogenous long or short siRNAs (Xie et al. 2004), and DCL3 is required exclusively for the production of long siRNAs (Xie et al. 2004), which have no apparent role in PTGS (Hamilton et al. 2002; Himber et al. 2003). The observations that $d c 14-2$ reduces the abundance of siR1511 and siR255 and causes incomplete processing of cleavage fragments of TAS2(+) and TAS1a $1+1$ suggests that DCL4 generates small siRNAs from these fragments. However, it is still unclear if it is the only DCL with this function because we have no evidence that $d c 14-2$ is a null mutation. The small siRNAs present in $d c 14-2$ could be the product of this mutant protein or could be generated by another DCL that also operates on these cleavage fragments. The best candidate is DCL1 because this enzyme generates 21-22-nt miRNAs. The presence of 24-nt forms of siR255 and siR1511 in dc14-2 suggests that DCL3 is also capable of processing these fragments. This issue will be resolved by the phenotypes of other $d c 14$ alleles and the phenotypes of double mutants between $d c 14$ and mutations in other DCL genes. DCL4 is the only DCL in Arabidopsis that lacks a PAZ domain (Schauer et al. 2002) and resembles the Drosophila dicer DCR2 in this respect (Lee et al. 2004). DCR2 is required for the biogenesis of siRNAs (Lee et al. 2004) and participates with R2D2 in loading siRNAs into RISC (Liu et al. 2003; Denli et al. 2004; Pham et al. 2004; Tomari et al. 2004). DCL4 may perform a similar function because its C-terminal domain has been shown to interact with the R2D2 homolog, DRB4 (Hiraguri et al. 2005).

\section{The evolution and function of TAS1 and TAS2}

TAS2 produces four different siRNAs directed against a recently expanded family of $P P R$ genes, so it is not unreasonable to predict that TAS2 evolved from a member of this family. Two features that distinguish TAS2(+) from its $P P R$ targets (aside from the fact that it is a noncoding transcript) are the presence of a miR173 target site and the fact that the region of similarity between TAS2 and its PPR targets lies in a large, differentially spliced intron. In contrast, the $P P R$ genes targeted by TAS2 either have no introns or a few small ones: The target sites for TAS2 ta-siRNAs reside in coding regions of these genes. Two key events in the evolution of TAS2 may have been the acquisition of a poorly spliced intron and the acquisition of a miRNA target site within this intron. Interestingly, the $P P R$ family from which TAS2 probably evolved is the same family that spawned the miRNA, miR161 (Allen et al. 2004). This suggests that pressure to coordinately repress the expression of recently duplicated genes is an important factor in the evolution of gene silencing mechanisms in plants.

Although TAS2 has no significant similarity to the TAS1 loci outside the miR173 site, there is convincing evidence that these loci are evolutionarily related. In addition to the structural similarity between TAS2(+) and TAS1 $a(+)$ and the similarity in the way these transcripts are processed, all three TAS1 loci are theoretically capable of producing at least one siRNA that targets the same family of PPR genes targeted by TAS2. Furthermore, TAS2 and TAS1C are immediately adjacent to each other on chromosome 2 and are in the same orientation. This organization suggests that TAS2 and TAS1c arose by a direct duplication and that TAS1 $a$ and TAS1b arose from TAS1c after it had diverged from TAS2. If TAS2 and the TAS1 loci are indeed paralogs, the number of unique tasiRNA loci that have been identified in Arabidopsis would be reduced to two: TAS1/TAS2 and TAS3.

The observation that T-DNA insertions in TAS2 and TAS1a (Vazquez et al. 2004b) do not have a major effect on shoot morphology indicates that these genes do not account for the developmental phenotype of mutations in SGS3, RDR6, and DCL4. TAS3 targets auxin-related genes known to be important in shoot morphogenesis, and it is possible that defects in the production of tasiRNAs from this locus are responsible for this developmental phenotype. Defining the endogenous targets of the SGS3/RDR6/DCL4 pathway, and the biological functions of these targets, are important goals for future research.

\section{Materials and methods}

\section{Genetic stocks and growth conditions}

The stocks of zip-1, sgs3-11, rdr6-11, xrn4-5, dc11-7, dcl2-1, dcl3-1 hst-6, and hyl1-2 used in this study were in a Columbia (Col) genetic background and have been described previously (Golden et al. 2002; Peragine et al. 2004; Souret et al. 2004; Vazquez et al. 2004a; Xie et al. 2004; Park et al. 2005). Double mutants were identified in F2 families using the allele-specific PCR primers described in these studies and were propagated as homozygous lines, except in the case of sgs3-11 dcl1-7, which was maintained as a sgs3-11/sgs3-11 +/dcl1-7 stock. dcl4-2 was identified in a screen of M2 families from EMS-mutagenized $\mathrm{Col}$ seeds and was backcrossed to Col three times before characterization. dcl4-2 rdr6-11 double mutants were identified using the PCR assay for $r d r 6-11$ described previously (Peragine et al. 2004) and a dCAPs marker for dc14-2. Amplification with the dcl4CAP primers followed by digestion with MboII yields two fragments in wild-type DNA and a single fragment in $d c 14-2$. 
Plants homozygous for the SALK_014168 T-DNA insertion were identified using the 014168-LP and 014168-RP primers. Plants were grown in soil in chambers under continuous fluorescent illumination $\left(22^{\circ} \mathrm{C}\right)$. Sequences of the PCR primers and oligonucleotide probes used in this study are provided in Supplementary Tables 1 and 2.

\section{Northern analysis}

Total RNA was isolated from flowers as previously described (Peragine et al. 2004). Poly(A) mRNA was isolated from total RNA by two rounds of purification using the Oligotex mRNA Midi kit (QIAGEN). LMW RNA was purified from total RNA according to Dalmay et al. (2000a). Total or poly(A) RNA were separated on agarose gels, blotted, and probed with randomly primed ${ }^{32} \mathrm{P}$-labeled probes (Stratagene) or with end-labeled oligonucleotide probes as previously described (Peragine et al. 2004). Double-stranded probes were hybridized overnight at $68^{\circ} \mathrm{C}$ in PerfectHyb Plus buffer (Sigma) according to the manufacturer's instructions. Oligonucleotide probes were hybridized overnight at $55^{\circ} \mathrm{C}$ in ULTRAhyb-oligo buffer (Ambion). Following hybridization, blots were washed twice in $2 \times$ SSC and $0.5 \%$ SDS for $30 \mathrm{~min}$ at $55^{\circ} \mathrm{C}$. LMW RNA was separated on $15 \%$ gels and transferred electrophoretically to Hybond $\mathrm{N}+$ membranes. LMW blots were processed at $40^{\circ} \mathrm{C}$ using ULTRAhyb-oligo buffer (oligonucleotide probes) or $38^{\circ} \mathrm{C}$ using PerfectHyb Plus buffer (ds probes) as described above. Double-stranded probes were generated from Col genomic DNA by PCR using the following primers: TAS2p1 (TAS2pr1 and TAS2pr3), TAS2p2 (TAS2pr1 and TAS2pr2), TAS2p3 (TAS2pr3 and TAS2pr4), TAS1ap1(TAS1aRACE1 and TASlapr1), and TAS1ap2 (ASRP752S and ASRP1927AS).

\section{Transcript analysis}

5' and 3' RACE were carried out using the GeneRacer Kit (Invitrogen). To identify the $5^{\prime}$ end of capped transcripts, the GeneRacer adaptor was ligated to mRNA (125 ng) previously treated with calf intestinal phosphatase (CIP) and tobacco acid phosphatase (TAP) according to the manufacturer's instructions. RLM-5'RACE was performed by directly ligating this adaptor to untreated mRNA. Fragments were amplified with Platinum $P f_{X}$ DNA polymerase (Invitrogen) or Taq DNA polymerase, purified, cloned into the TOPO (Invitrogen) or pGEM-T Easy (Promega) cloning vectors, and then sequenced. RNA was amplified by nested PCR, using the adaptor primers supplied by the manufacturer in combination with gene-specific primers. RLM-5'RACE of the PPR and TAS1 $1+\mid$ transcripts was performed using RACE1 primers, followed by RACE2 (Supplementary Table 1). 5' RACE of TAS2(+) was performed using TAS2pr5, followed by TAS2pr6, TAS2pr7, or TAS2pr8. 3' RACE of TAS2 (+) was performed using the GeneRacer 3' adaptor primers in combination with TAS2pr9 and TAS2pr10.

Self-ligated transcripts were generated as previously described (Couttet et al. 1997). Briefly, total RNA (4 $\mu$ g) from Col flowers was treated with RQ1 DNase (Promega), CIP, and TAP and incubated in a volume of $400 \mu \mathrm{L}$ with T4 RNA ligase for $16 \mathrm{~h}$ at $16^{\circ} \mathrm{C}$. cDNA synthesis was carried out using SuperScriptII reverse transcriptase (Invitrogen) and TAS2pr11, and the resulting products were amplified by PCR using the TAS2pr12 and pr13 primers. PCR fragments were gel-purified, cloned into the TOPO cloning vector, and then sequenced.

\section{$R T-P C R$}

Total RNA was purified after extraction using RNeasy and RNase-Free DNase (Qiagen). Further removal of genomic DNA was accomplished by treating samples with RQ1 DNase and then extracting RNA with acidic phenol/chloroform. Quantitative real-time RT-PCR was carried out using the primers 62930-F and 62930-R for At1g62930, 63130-F and 63130-R for Atlg63130, 63230-F and 63230-R for Atlg63230, SCL6-IV-F and SCL6-IV-R for SCL6-IV, and EIF4A-F and EIF4A-R for EIF4A.

\section{Acknowledgments}

We are grateful to Christine Hunter, Matthew Willmann, and Eric Moss for helpful comments on this manuscript. We also thank the Arabidopsis Biological Resource Center, the FST project, Animesh Ray, and Pam Green for seed stocks used in these experiments. This research was supported by a fellowship from the National Institute of Agrobiological Sciences (Japan) to M.Y. and grants from the NIH and NSF to R.S.P.

\section{References}

Allen, E., Xie, Z., Gustafson, A.M., Sung, G.H., Spatafora, J.W., and Carrington, J.C. 2004. Evolution of microRNA genes by inverted duplication of target gene sequences in Arabidopsis thaliana. Nat. Genet. 36: 1282-1290.

Allen, E., Xie, Z., Gustafson, A.M., and Carrington, J.C. 2005. microRNA-directed phasing during trans-acting siRNA biogenesis in plants. Cell 121: 207-221.

Ambros, V. 2004. The functions of animal microRNAs. Nature 431: 350-355.

Ambros, V., Lee, R.C., Lavanway, A., Williams, P.T., and Jewell, D. 2003. MicroRNAs and other tiny endogenous RNAs in $C$. elegans. Curr. Biol. 13: 807-818.

Aravin, A.A., Naumova, N.M., Tulin, A.V., Vagin, V.V., Rozovsky, Y.M., and Gvozdev, V.A. 2001. Double-stranded RNA-mediated silencing of genomic tandem repeats and transposable elements in the D. melanogaster germline. Curr. Biol. 11: 1017-1027.

Aravin, A.A., Lagos-Quintana, M., Yalcin, A., Zavolan, M., Marks, D., Snyder, B., Gaasterland, T., Meyer, J., and Tuschl, T. 2003. The small RNA profile during Drosophila melanogaster development. Dev. Cell 5: 337-350.

Bao, N., Lye, N.W., and Barton, M.K. 2004. MicroRNA binding sites in Arabidopsis class III HD-ZIP mRNAs are required for methylation of the template chromosome. Dev. Cell 7: 653-662.

Bartel, D.P. 2004. MicroRNAs: Genomics, biogenesis, mechanism, and function. Cell 116: 281-297.

Bateman, A. 2002. The SGS3 protein involved in PTGS finds a family. BMC Bioinformatics 3: 21 .

Beclin, C., Boutet, S., Waterhouse, P., and Vaucheret, H. 2002. A branched pathway for transgene-induced RNA silencing in plants. Curr. Biol. 12: 684-688.

Chicas, A., Cogoni, C., and Macino, G. 2004. RNAi-dependent and RNAi-independent mechanisms contribute to the silencing of RIPed sequences in Neurospora crassa. Nucleic Acids Res. 32: 4237-4243.

Couttet, P., Fromont-Racine, M., Steel, D., Pictet, R., and Grange, T. 1997. Messenger RNA deadenylylation precedes decapping in mammalian cells. Proc. Natl. Acad. Sci. 94: 5628-5633.

Dalmay, T., Hamilton, A., Mueller, E., and Baulcombe, D.C. 2000a. Potato virus X amplicons in Arabidopsis mediate genetic and epigenetic gene silencing. Plant Cell 12: 369-379.

Dalmay, T., Hamilton, A., Rudd, S., Angell, S., and Baulcombe, D.C. 2000 b. An RNA-dependent RNA polymerase gene in 
Arabidopsis is required for posttranscriptional gene silencing mediated by a transgene but not by a virus. Cell 101: 543-553.

Denli, A.M., Tops, B.B., Plasterk, R.H., Ketting, R.F., and Hannon, G.J. 2004. Processing of primary microRNAs by the Microprocessor complex. Nature 432: 231-235.

Djikeng, A., Shi, H., Tschudi, C., and Ullu, E. 2001. RNA interference in Trypanosoma brucei: Cloning of small interfering RNAs provides evidence for retroposon-derived 24-26nucleotide RNAs. RNA 7: 1522-1530.

Elbashir, S.M., Lendeckel, W., and Tuschl, T. 2001. RNA interference is mediated by 21- and 22-nucleotide RNAs. Genes \& Dev. 15: 188-200.

Finnegan, E.J., Margis, R., and Waterhouse, P.M. 2003. Posttranscriptional gene silencing is not compromised in the Arabidopsis CARPEL FACTORY (DICER-LIKE1) mutant, a homolog of Dicer-1 from Drosophila. Curr. Biol. 13: 236-240.

Gazzani, S., Lawrenson, T., Woodward, C., Headon, D., and Sablowski, R. 2004. A link between mRNA turnover and RNA interference in Arabidopsis. Science 306: 1046-1048.

Golden, T.A., Schauer, S.E., Lang, J.D., Pien, S., Mushegian, A.R., Grossniklaus, U., Meinke, D.W., and Ray, A. 2002. SHORT INTEGUMENTS1/SUSPENSOR1/CARPEL FACTORY, a Dicer homolog, is a maternal effect gene required for embryo development in Arabidopsis. Plant Physiol. 130: $808-822$.

Gu, S. and Rossi, J.J. 2005. Uncoupling of RNAi from active translation in mammalian cells. RNA 11: 38-44.

Gustafson, A.M., Allen, E., Givan, S., Smith, D., Carrington, J.C., and Kasschau, K.D. 2005. ASRP: The Arabidopsis Small RNA Project Database. Nucleic Acids Res. 33: D637-D640.

Hamilton, A.J. and Baulcombe, D.C. 1999. A species of small antisense RNA in posttranscriptional gene silencing in plants. Science 286: 950-952.

Hamilton, A., Voinnet, O., Chappell, L., and Baulcombe, D. 2002. Two classes of short interfering RNA in RNA silencing. EMBO J. 21: 4671-4679.

Han, M.H., Goud, S., Song, L., and Fedoroff, N. 2004. The Arabidopsis double-stranded RNA-binding protein HYL1 plays a role in microRNA-mediated gene regulation. Proc. Natl. Acad. Sci. 101: 1093-1098.

Herr, A.J., Jensen, M.B., Dalmay, T., and Baulcombe, D.C. 2005. RNA polymerase IV directs silencing of endogenous DNA. Science 308: 118-120.

Himber, C., Dunoyer, P., Moissiard, G., Ritzenthaler, C., and Voinnet, O. 2003. Transitivity-dependent and -independent cell-to-cell movement of RNA silencing. EMBO J. 22: 45234533.

Hiraguri, A., Itoh, R., Kondo, N., Nomura, Y., Aizawa, D., Murai, Y., Koiwa, H., Seki, M., Shinozaki, K., and Fukuhara, T. 2005. Specific interactions between Dicer-like proteins and HYL1/DRB-family dsRNA-binding proteins in Arabidopsis thaliana. Plant Mol. Biol. 57: 173-188.

Kasschau, K.D., Xie, Z., Allen, E., Llave, C., Chapman, E.J., Krizan, K.A., and Carrington, J.C. 2003. P1/HC-Pro, a viral suppressor of RNA silencing, interferes with Arabidopsis development and miRNA function. Dev. Cell 4: 205-217.

Ketting, R.F., Fischer, S.E., Bernstein, E., Sijen, T., Hannon, G.J., and Plasterk, R.H. 2001. Dicer functions in RNA interference and in synthesis of small RNA involved in developmental timing in C. elegans. Genes \& Dev. 15: 2654-2659.

Kidner, C.A. and Martienssen, R.A. 2005. The developmental role of microRNA in plants. Curr. Opin. Plant Biol. 8: 38-44.

Lee, R.C., Feinbaum, R.L., and Ambros, V. 1993. The C. elegans heterochronic gene lin-4 encodes small RNAs with antisense complementarity to lin-14. Cell 75: 843-854.
Lee, Y.S., Nakahara, K., Pham, J.W., Kim, K., He, Z., Sontheimer, E.J., and Carthew, R.W. 2004. Distinct roles for Drosophila Dicer-1 and Dicer-2 in the siRNA/miRNA silencing pathways. Cell 117: 69-81.

Liu, X. and Gorovsky, M.A. 1993. Mapping the 5' and 3' ends of Tetrahymena thermophila mRNAs using RNA ligase mediated amplification of cDNA ends (RLM-RACE). Nucleic Acids Res. 21: 4954-4960.

Liu, Q., Rand, T.A., Kalidas, S., Du, F., Kim, H.E., Smith, D.P., and Wang, X. 2003. R2D2, a bridge between the initiation and effector steps of the Drosophila RNAi pathway. Science 301: 1921-1925.

Liu, J., He, Y., Amasino, R., and Chen, X. 2004. siRNAs targeting an intronic transposon in the regulation of natural flowering behavior in Arabidopsis. Genes \& Dev. 18: 2873-2878.

Llave, C., Kasschau, K.D., Rector, M.A., and Carrington, J.C. 2002a. Endogenous and silencing-associated small RNAs in plants. Plant Cell 14: 1605-1619.

Llave, C., Xie, Z., Kasschau, K.D., and Carrington, J.C. $2002 \mathrm{~b}$. Cleavage of Scarecrow-like mRNA targets directed by a class of Arabidopsis miRNA. Science 297: 2053-2056.

Lurin, C., Andres, C., Aubourg, S., Bellaoui, M., Bitton, F., Bruyere, C., Caboche, M., Debast, C., Gualberto, J., Hoffmann, B., et al. 2004. Genome-wide analysis of Arabidopsis pentatricopeptide repeat proteins reveals their essential role in organelle biogenesis. Plant Cell 16: 2089-2103.

Maquat, L.E. 2004. Nonsense-mediated mRNA decay: Splicing, translation and mRNP dynamics. Nat. Rev. Mol. Cell Biol. 5: 89-99.

Mourrain, P., Beclin, C., Elmayan, T., Feuerbach, F., Godon, C., Morel, J.B., Jouette, D., Lacombe, A.M., Nikic, S., Picault, N., et al. 2000. Arabidopsis SGS2 and SGS3 genes are required for posttranscriptional gene silencing and natural virus resistance. Cell 101: 533-542.

Muangsan, N., Beclin, C., Vaucheret, H., and Robertson, D. 2004. Geminivirus VIGS of endogenous genes required SGS2/SDE1 and SGS3 and defines a new branch in the genetic pathway for silencing in plants. Plant J. 38: 1004-1014.

Onodera, Y., Haag, J.R., Ream, T., Nunes, P.C., Pontes, O., and Pikaard, C.S. 2005. Plant nuclear RNA polymerase IV mediates siRNA and DNA methylation-dependent heterochromatin formation. Cell 120: 613-622.

Park, W., Li, J., Song, R., Messing, J., and Chen, X. 2002. CARPEL FACTORY, a Dicer homolog, and HEN1, a novel protein, act in microRNA metabolism in Arabidopsis thaliana. Curr. Biol. 12: 1484-1495.

Park, M.Y., Wu, G., Gonzalez-Sulser, A., Vaucheret, H., and Poethig, R.S. 2005. Nuclear processing and export of microRNAs in Arabidopsis. Proc. Natl. Acad. Sci. 102: 3691-3696.

Peragine, A., Yoshikawa, M., Wu, G., Albrecht, H.L., and Poethig, R.S. 2004. SGS3 and SGS2/SDE1/RDR6 are required for juvenile development and the production of trans-acting siRNAs in Arabidopsis. Genes \& Dev. 18: 2368-2379.

Pham, J.W., Pellino, J.L., Lee, Y.S., Carthew, R.W., and Sontheimer, E.J. 2004. A Dicer-2-dependent 80s complex cleaves targeted mRNAs during RNAi in Drosophila. Cell 117: 8394.

Reinhart, B.J., Slack, F.J., Basson, M., Pasquinelli, A.E., Bettinger, J.C., Rougvie, A.E., Horvitz, H.R., and Ruvkun, G. 2000. The 21-nucleotide let-7 RNA regulates developmental timing in Caenorhabditis elegans. Nature 403: 901-906.

Reinhart, B.J., Weinstein, E.G., Rhoades, M.W., Bartel, B., and Bartel, D.P. 2002. MicroRNAs in plants. Genes \& Dev. 16: $1616-1626$.

Rudenko, G.N., Ono, A., and Walbot, V. 2003. Initiation of si- 
lencing of maize MuDR/Mu transposable elements. Plant J. 33: 1013-1025.

Schauer, S.E., Jacobsen, S.E., Meinke, D.W., and Ray, A. 2002. DICER-LIKE1: Blind men and elephants in Arabidopsis development. Trends Plant Sci. 7: 487-491.

Schiebel, W., Haas, B., Marinkovic, S., Klanner, A., and Sanger, H.L. 1993. RNA-directed RNA polymerase from tomato leaves. II. Catalytic in vitro properties. J. Biol. Chem. 268: 11858-11867.

Shen, B. and Goodman, H.M. 2004. Uridine addition after microRNA-directed cleavage. Science 306: 997.

Sijen, T. and Plasterk, R.H. 2003. Transposon silencing in the Caenorhabditis elegans germ line by natural RNAi. Nature 426: 310-314.

Siolas, D., Lerner, C., Burchard, J., Ge, W., Linsley, P.S., Paddison, P.J., Hannon, G.J., and Cleary, M.A. 2004. Synthetic shRNAs as potent RNAi triggers. Nat. Biotechnol. 23: 227-231

Souret, F.F., Kastenmayer, J.P., and Green, P.J. 2004. AtXRN4 degrades mRNA in Arabidopsis and its substrates include selected miRNA targets. Mol. Cell 15: 173-183.

Tang, G., Reinhart, B.J., Bartel, D.P., and Zamore, P.D. 2003. A biochemical framework for RNA silencing in plants. Genes \& Dev. 17: 49-63.

Tomari, Y. and Zamore, P.D. 2005. Perspective: Machines for RNAi. Genes \& Dev. 19: 517-529.

Tomari, Y., Matranga, C., Haley, B., Martinez, N., and Zamore, P.D. 2004. A protein sensor for siRNA asymmetry. Science 306: $1377-1380$.

Vaistij, F.E., Jones, L., and Baulcombe, D.C. 2002. Spreading of RNA targeting and DNA methylation in RNA silencing requires transcription of the target gene and a putative RNAdependent RNA polymerase. Plant Cell 14: 857-867.

Vazquez, F., Gasciolli, V., Crete, P., and Vaucheret, H. 2004a. The nuclear dsRNA binding protein HYL1 is required for MicroRNA accumulation and plant development, but not posttranscriptional transgene silencing. Curr. Biol. 14: 346351.

Vazquez, F., Vaucheret, H., Rajagopalan, R., Lepers, C., Gasciolli, V., Mallory, A.C., Hilbert, J.L., Bartel, D.P., and Crete, P. 2004b. Endogenous trans-acting siRNAs regulate the accumulation of Arabidopsis mRNAs. Mol. Cell 16: 6979 .

Williams, L., Carles, C.C., Osmont, K.S., and Fletcher, J.C. 2005. A database analysis method identifies an endogenous trans-acting short-interfering RNA that targets the Arabidopsis ARF2, ARF3, and ARF4 genes. Proc. Nat1. Acad. Sci. 102: 9703-9708.

Xie, Z., Johansen, L.K., Gustafson, A.M., Kasschau, K.D., Lellis, A.D., Zilberman, D., Jacobsen, S.E., and Carrington, J.C. 2004. Genetic and functional diversification of small RNA pathways in plants. PLoS Biol. 2: 642-652.

Yu, B., Yang, Z., Li, J., Minakhina, S., Yang, M., Padgett, R.W., Steward, R., and Chen, X. 2005. Methylation as a crucial step in plant microRNA biogenesis. Science 307: 932-935.

Zhang, H., Kolb, F.A., Brondani, V., Billy, E., and Filipowicz, W. 2002. Human Dicer preferentially cleaves dsRNAs at their termini without a requirement for ATP. EMBO J. 21: 58755885.

Zhang, H., Kolb, F.A., Jaskiewicz, L., Westhof, E., and Filipowicz, W. 2004. Single processing center models for human Dicer and bacterial RNase III. Cell 118: 57-68.

Zilberman, D., Cao, X., and Jacobsen, S.E. 2003. ARGONAUTE4 control of locus-specific siRNA accumulation and DNA and histone methylation. Science 299: 716-719. 


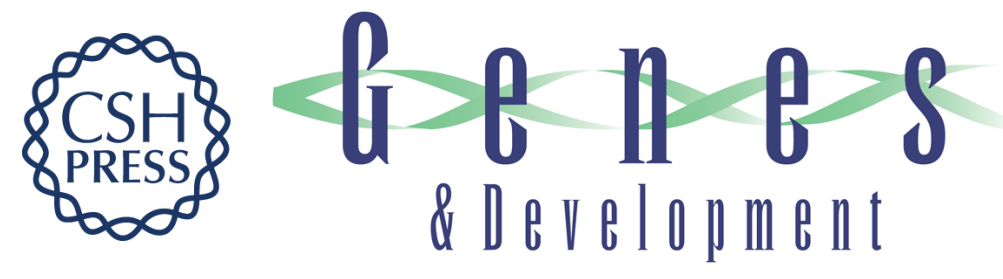

\section{A pathway for the biogenesis of trans-acting siRNAs in Arabidopsis}

Manabu Yoshikawa, Angela Peragine, Mee Yeon Park, et al.

Genes Dev. 2005, 19:

Access the most recent version at doi:10.1101/gad.1352605

Supplemental http://genesdev.cshlp.org/content/suppl/2005/08/31/gad.1352605.DC1

Material

References This article cites 66 articles, 31 of which can be accessed free at:

http://genesdev.cshlp.org/content/19/18/2164.full.html\#ref-list-1

License

Email Alerting Receive free email alerts when new articles cite this article - sign up in the box at the top Service right corner of the article or click here.

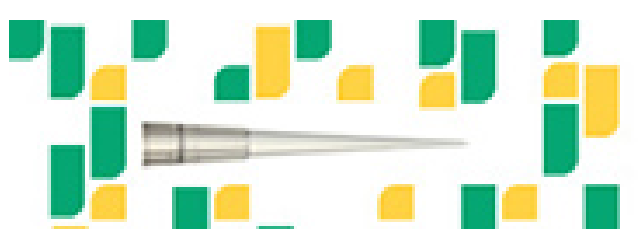

Focused on your science. 